IZA DP No. 3716

Trade and Location with Land as a Productive Factor

Michael Pflüger

Takatoshi Tabuchi

September 2008 


\title{
Trade and Location with Land as a Productive Factor
}

\author{
Michael Pflüger \\ University of Passau, \\ DIW Berlin and IZA \\ Takatoshi Tabuchi \\ University of Tokyo
}

\section{Discussion Paper No. 3716 \\ September 2008}

\author{
IZA \\ P.O. Box 7240 \\ 53072 Bonn \\ Germany \\ Phone: +49-228-3894-0 \\ Fax: +49-228-3894-180 \\ E-mail: iza@iza.org
}

Any opinions expressed here are those of the author(s) and not those of IZA. Research published in this series may include views on policy, but the institute itself takes no institutional policy positions.

The Institute for the Study of Labor (IZA) in Bonn is a local and virtual international research center and a place of communication between science, politics and business. IZA is an independent nonprofit organization supported by Deutsche Post World Net. The center is associated with the University of Bonn and offers a stimulating research environment through its international network, workshops and conferences, data service, project support, research visits and doctoral program. IZA engages in (i) original and internationally competitive research in all fields of labor economics, (ii) development of policy concepts, and (iii) dissemination of research results and concepts to the interested public.

IZA Discussion Papers often represent preliminary work and are circulated to encourage discussion. Citation of such a paper should account for its provisional character. A revised version may be available directly from the author. 
IZA Discussion Paper No. 3716

September 2008

\section{ABSTRACT}

\section{Trade and Location with Land as a Productive Factor ${ }^{*}$}

This paper is motivated by the fact that, contrary to its importance in practice, the role of land for production has received no attention in the new trade theory and the new economic geography. We set up a simple monopolistic competition model and we show that, due to the factor proportions effect which emerges when land is used as a productive factor besides labor, a number of tenets of the new trade and geography literature no longer hold. We also show that in order to explain the stylized facts, notably that wages are higher in larger locations, land-use for production and housing has to be taken into account. Our analysis furthermore implies that market-size based agglomeration forces are too weak to overcome the very strong congestion force associated with competition for land, unless the consumers' desire of variety (as expressed by a low elasticity of substitution) is very strong. This suggests that further agglomeration forces have to be invoked to explain the agglomeration of economic activity observed in the real world.

JEL Classification: F12, F22, R12

Keywords: trade and location, land for production, agglomeration, relative wage, home market effect

Corresponding author:

Michael Pflüger

Faculty of Economics

University of Passau

Innstrasse 27

94032 Passau

Germany

E-mail: michael.pflueger@uni-passau.de

\footnotetext{
* Paper presented at research seminars in Leipzig and Nagoya and at the annual meeting of the Verein für Socialpolitik in Graz. We thank Kristian Behrens, Gilles Duranton, Masahisa Fujita, Thomas Steger and Jens Südekum for discussion and helpful comments. Part of this paper was written while Pflüger was visiting IZA Bonn. He wishes to express his gratitude for their hospitality.
} 


\section{$1 \quad$ Introduction}

The development of the core-periphery agglomeration model by Krugman (1991) which builds on his work in new trade theory (Krugman 1979, 1980) has brought spatial economics back into the awareness of a wide audience of economists. However, the concept of space so often used in the new economic geography (NEG) is a rather narrow one. Following the tradition of the theory of international trade, usually two regions are considered as two separate 'dots' in space and trade between them is assumed to be costly for at least some of the goods. More elaborate concepts of space have been introduced into this field of research mainly in the form of congestion costs associated with scarce housing (e.g. Helpman 1998) or in the form of urban costs arising in extensions of cities around a central business district (e.g. Krugman and Livas Elizondo 1996; Tabuchi 1998).

What strikes us as having been overlooked so far in the new trade theory and the new economic geography is the role of land as a productive factor in those branches of the economy on which these theories put their focus: the branches where production takes place under increasing returns to scale. The increasing returns sector, aptly called the 'modern' one, presently should be seen to comprise activities in manufacturing and in services (Ottaviano and Thisse 2004). Taking stock of recent research, Combes et al. (2005: 313) note: "The role of land for production has received surprisingly little attention. It is ignored in NEG, while in the urban systems literature it plays a key role in housing, but not production." In fact, we are not aware of a single contribution which considers land for production in the increasing returns sector. ${ }^{1}$

The evidence indicates that land-use for production of goods and services is important. For example in Germany in $2004,11.996 \mathrm{~km}^{2}$ (or $45 \%$ of the 'built-up area in use') were for production as compared to (only) $10.004 \mathrm{~km}^{2}$ (or $37,5 \%$ of the 'built-up area in use') for housing. ${ }^{2}$ Without a proper analysis it is impossible to judge how serious this neglect of the factual importance of land-use for productive purposes for our understanding of the space economy is. From this perspective it is desirable to find out whether and (possibly) how the basic tenets of the new trade and the new economic geography are affected when the

\footnotetext{
${ }^{1}$ However, land has been considered a productive factor in addition to labor in the 'traditional' constant returns sector in Puga (1999) and, in an implicit way, in Fujita et al. (1999: chapt. 14).

${ }^{2}$ The remaining $17,5 \%$ of the 'built-up area in use' are recreation areas and cemeteries. Land-use for production in Germany is itself split into $29.9 \%$ for manufacturing, $47,3 \%$ for services and $22.8 \%$ for agricultural production (this does not include the areas under cultivation). The 'built-up area in use' comprised $7.9 \%$, the built-up area unused $0.42 \%$ and the traffic area $4.9 \%$ of the total area of Germany $\left(357.050 \mathrm{~km}^{2}\right)$, the remaining parts are agricultural areas, forests and sheets of water (Statistisches Bundesamt 2008, http://www.destatis.de).
} 
productive use of land is taken into account: Will a larger country still have larger wages as suggested in the seminal analysis by Krugman (1980)? How is the balance between agglomerative and deglomerative tendencies affected? Do the welfare implications that have been derived in models with land for housing carry over? Is land-use for productive purposes simply equivalent in its implications as when land is used for housing?

The main contribution of this paper is to set up a minimal model which allows us to provide answers to these questions. We deliberately follow the methodology of imposing 'aggressively unrealistic assumptions' (Fujita et al. 1999) to work out the implications of land as a productive factor as sharply and as simple as possible. In line with the factual dominance of land-use for production we start out with the extreme assumption that no space is needed for housing. The production of goods and services is assumed to take place under increasing returns to scale with firms using labor and land: their fixed cost consists of labor, only; their variable cost consists of land, only, as in the simplest formalizations of the Thünen model (e.g. Fujita and Thisse 2002). Trade costs of the iceberg type are assumed to apply when goods and services are shipped between the two regions that we consider. We view it as a strength of our simple model that it sidesteps two assumptions which are very often imposed in the trade and geography literature: there is no outside good in our model which is traded at no cost; moreover, we do not assume the existence of a class of immobile 'farmers'; rather, when we switch from the 'trade regime' where labor is internationally immobile and only intra-industry trade takes place between the two regions, to a 'geography regime', where, in addition, workers are mobile across borders, we assume that all of them are mobile.

Our analysis yields a number of striking conclusions. First, in the 'trade regime', the larger country has the lower wage, in general. This result is in stark contrast to the finding of Krugman (1980). The reason for this discrepancy lies in the fact that, when land in addition to labor is needed for production, there is a factor proportions effect which counteracts the terms-of-trade effect that drives the result in Krugman (1980). We show that this factor proportion effect dominates in the trade regime when the elasticity of substitution between varieties is 'high' enough.

Second, in the 'geography regime', our model features market size effects familiar from the new economic geography and is thus able to explain agglomeration. Agglomeration is more likely to occur if the consumers' love of variety is strong (as expressed by a low elasticity of substitution) and, hence, if the market power of firms is strong. Our previous finding that the larger region has lower wages comes through even stronger than in the trade regime: we show 
that whenever an asymmetric distribution of labor is a stable equilibrium, the wage in the region with the higher share of labor and firms is always lower than the wage in the (partial) periphery. Moreover, in contrast to standard new economic geography models (e.g. Krugman 1991), the symmetry breaking level of trade freeness is decreasing in the elasticity of substitution, in general. There is a set of parameters where the model exhibits a smooth bellshaped pattern in the process of trade integration between two regions (i.e. dispersion followed by agglomeration followed by redispersion) even though there are no immobile 'farmers' in the model (the usual force for dispersion at high trade costs). However, this set of parameters is only a small subset of the range where agglomeration can occur. If agglomeration occurs in our model, the regular case is dispersion at low trade costs and increasing degrees of agglomeration with rising trade costs, resembling the location pattern that emerges in Helpman (1998), where land is used for housing, only. Hence, our result is consistent with empirical research which finds it rather hard to detect trade-induced agglomeration. ${ }^{3}$

Third, in contrast to analyses which focus on land-use for housing (e.g. Helpman 1998), our welfare analysis indicates that the market solution involves excessive (rather than to little) agglomeration when land is used for production. This finding suggests that the welfare implications of agglomeration models based on market-size effects and pecuniary externalities may even be more fragile than previously thought.

Surprisingly then, a number of central tenets of the new trade theory and the new economic geography cease to hold once we account for the fact that land is used as a productive factor. However, it must then also be acknowledged that our model, even though correctly reflecting the factual dominance of land-use for production, is at odds with two empirical facts. Larger locations tend to have higher (nominal) wages. This empirical fact is particularly well-known to hold for cities where it is termed the 'urban wage premium' (e.g. Glaeser and Maré 2001; Yankow 2006; Gould 2007) but it has also been documented at the levels of regions and nations (e.g. Head and Mayer 2004 and Amiti and Cameron 2007). Furthermore, the cost of living is higher in larger location, as documented in the empirical literature already cited. ${ }^{4}$

To account for these stylized facts we modify our model. We retain the specification of technology but, following Helpman (1998), assume that consumers have Cobb-Douglas

\footnotetext{
${ }^{3}$ Taking stock of the empirical literature, Head and Mayer (2004) explicitly note that, to their surprise, the most convincing evidence avalaible militates in favor of Helpman's model.

${ }^{4}$ It is well-known that standard new economic geography models (e.g. Krugman 1991) are at odds with this fact, too (Südekum 2006).
} 
preferences over (non-produced and non-traded) housing and the differentiated varieties produced in the modern sector. This parsimonious modification suffices to reconcile our model with the facts on wages and prices. Moreover, the previous conclusions that (i) the symmetry breaking level of trade freeness is decreasing in the elasticity of substitution, in general, and that a bell-shaped location pattern may emerge in a process of trade integration and that (ii) there is market over-agglomeration, in contrast to models which focus on landuse for housing only, remain valid in this modification of the model.

A final important result of our analysis has to do with the numerical value that the elasticity of substitution has to take on for our model to generate agglomeration: both in the version with land-use for production only as well as in the version with land-use for production and housing, this elasticity has to be rather low (roughly in the range of 2 or less) for the model to imply agglomeration. This is much lower than the values that are implied by empirical estimates of price mark-ups whilst agglomeration is nonetheless observed in the real world. This observation merits two comments. First, this discrepancy is easily explained by the very stylized nature of our model, which, quite purposefully rules out any asymmetries between the two locations: full dispersion (i.e. an equal division of firms) would never arise in our model once we allowed for asymmetric land endowments, for example. A second and even deeper point that emerges from our analysis is that the market-size based agglomeration forces stressed in the new economic geography may simply be too weak to overcome the very strong congestion force associated with competition for land, unless the consumers desire of variety (as expressed by a very low elasticty of substitution) is very strong. In turn this suggests, that one has to resort to further complementary agglomeration forces such as e.g. knowledge spillovers to explain the agglomeration of economic activity that is observed in the real world.

The organization of the paper is as follows. The next section explains how our analysis relates to the previous literature. The model with land-use for productive purposes is introduced in section 3. Sections 4 and 5 cover the 'trade regime' and the 'geography regime' where labor is assumed to be internationally immobile and mobile, respectively. Section 6 contains the analysis where land is used both for housing and production. Section 7 concludes.

\section{Review of the literature}

Our analysis contributes to several strands of research in which the foundations of the new trade theory and the new economic geography are put under scrutiny. 
First, by considering land as a productive factor, our paper adds to the literature which highlights the interplay between intra-firm scale economies, trade costs and market size on the one hand and factor proportions, and, hence comparative advantage, on the other hand. The previous literature has ignored the immobile factor land altogether, focussing on mobile capital and country size differences, factor intensities, trade cost differentials and differences in the substitution parameters, instead. Most of these works elaborate on the 'wage differential effect' that is prevalent in the Krugman (1980) one-sector model (the larger country has a higher wage), the related 'home market effect' that obtains in the Krugman (1980) and Helpman and Krugman (1985) two-sector model (the larger country has a disproportionate share of industry and, hence, is a net-exporter of these goods) and Krugman's (1991) explanation of endogenous agglomeration based on market size effects. Seminal contributions are by Martin and Rogers (1995) who set up a tractable model with mobile capital which exhibits the home market effect but not the wage-differential effect, whereas the less tractable trade model by Amiti (1998) features the tension between those two and so do the models of Laussel and Paul (2007) and Holmes and Stevens (2005) which build on Amiti but stick to specifications involving only one factor of production (labor) and a non-Dixit-Stiglitz-world, respectively. There are also works that consider the interplay of factor proportions and the agglomeration forces stressed in the new economic geography such as Ihara (2005), who integrates interregionally mobile capital in the short-run and mobile labor in the long-run into the standard core-periphery model and Amiti (2005) who uses a model with vertical linkages.

Our paper also contributes to a second strand of research which reconsiders the assumption of a costlessly traded good which is often met in new trade theory and economic geography even though it is deemed deeply unsatisfactory both empirically and theoretically (Ottaviano and Thisse 2004). Davis (1998) makes the point that the home market effect vanishes in Krugman's two-sector model when both the increasing returns sector and the constant returns outside good are shipped at the same cost. Subsequent work by Fujita et al. (1999) and others shows that the home market effect is re-established when the output in the constant returns sector is differentiated across regions. ${ }^{5}$ Our analysis is in line with the works by Krugman and Livas Elizondo (1996), Helpman (1998) and Murata (2003) which avoid the assumption of a costlessly traded good by simply focussing on one 'modern sector' whose differentiated output is traded at a cost. These previous works do not consider land as a productive factor, however.

Third, our analysis connects with a strand of research which challenges the assumption of an

\footnotetext{
${ }^{5}$ Ottaviano and Thisse (2004) provide a brief survey of the discussion.
} 
immobile labor force, the 'farmers' in Krugman's (1991) parlance. This assumption is made to have a dispersion force which counteracts the agglomerative forces. A way out of this ad-hoc assumption is to bring in other dispersion forces such as heterogeneous tastes for location as in Tabuchi and Thisse (2002) and Murata (2003) or congestion effects in the housing market as in Krugman and Livas Elizondo (1996) and Helpman (1998). These works are usually tied up with the second strand and so is our approach. The difference of our analysis to previous works is that ours is the first to highlight the role of land as a productive factor.

Finally, our analysis is related to a literature which explores the welfare implications of the new economic geography. The most important general finding of these works is that due to the pecuniary externalities associated with the migration of workers in imperfectly competitive markets, the market equilibrium and the social optimum may fall apart. Since distribution effects make the Pareto criterion inapplicable, this literature has often made use of the utilitarian social welfare function, in particular when agents are assumed to have quasilinear preferences, where this assumption is particularly well-suited. However, this criterion is only one of various possible welfare criteria. Other works have used compensation mechanisms or the Rawlsian welfare criterion (e.g. Helpman 1998 and Charlot et al. 2006). Charlot et al. (2006) show that utilitarianism may be biased towards agglomeration with other (e.g. Cobb-Douglas) preferences. Moreover, some of the literature has addressed the first-best optimum where a benevolent social planner is assumed to choose both marginal cost prices and the allocation of labor, whereas many works have focused on a second-best optimum, only, where the market power of firms is not addressed. These caveats in mind, the findings of the previous literature can be roughly summarized as follows. ${ }^{6}$ First, in the absence of land for housing but in the presence of immobile demand (i.e. immobile farmers), the market outcome involves over-agglomeration for intermediate trade costs. ${ }^{7}$ Second, in the presence of land for housing, but in the absence of immobile demand, the market outcome involves underagglomeration for intermediate trade costs. ${ }^{8}$ Third, in the presence of both land for housing and immobile demand, the market outcome involves over-agglomeration for high trade costs and under-agglomeration for low trade costs. ${ }^{9}$ One might have expected that with land used for production and absent immobile demand a qualitatively similar result would obtain as in

\footnotetext{
${ }^{6}$ The following discussion focuses on the 'labor mobility framework' of the new economic geography. An indepth exploration of the welfare implications of the alternative 'vertical linkages framework' is provided in Ottaviano and Robert-Nicoud (2006).

${ }^{7}$ See proposition 2 in Ottaviano, Tabuchi and Thisse (2002), Ottaviano and Thisse (2002) and propositions 1(i) and 3 in Pflüger and Südekum (2008).

${ }^{8}$ See Helpman (1998), proposition 2 in Tabuchi and Thisse (2002b) and proposition 4 in Murata (2003).

${ }^{9}$ See figure 2 in Ottaviano, Tabuchi and Thisse (2002), figure 3(ii) in Tabuchi and Thisse (2002a) as well as Russek (2008) and proposition 1 in Pflüger and Südekum (2008).
} 
the second set of analyses, where land is used for housing. However, we show that the market equilibrium involves over-agglomeration when land is used for production both without and in combination with land-use for housing.

\section{The model}

\subsection{The basic framework}

We use a suitable extension of the one-sector Dixit-Stiglitz model considered in Krugman (1980). The economy consists of two regions. Consumers have a taste for variety in the manner described in Dixit and Stiglitz (1977). Trade costs of the iceberg type have to be incurred when a good is imported from the other region and firms are monopolistic competitors using an increasing returns technology to produce one variety of a differentiated good, each. Production takes place with two factors, labor and land. In order to render the model as tractable as possible, the technology for producing differentiated goods is assumed to be non-homothetic: ${ }^{10}$ labor is assumed to enter only in the fixed cost and land only in the variable cost, clearly an extreme assumption. However, it captures in a stylized way that labor is the major component of fixed costs in many sectors (e.g. for management, marketing activities, $\mathrm{R}+\mathrm{D}$ ) whilst the actual production processes make intensive use of land (e.g. offices and administrative buildings) following von Thünen (1826). Moreover, even though both labor and land are by assumption homogeneous in our model, this stylized characterization of technology also fits nicely with the fact that labor is more heterogeneous than the land that is used for productive purposes, in reality. Hence, labor appears to be the natural choice for the essential fixed input of the production of differentiated products whereas land seems to be the more natural one for the marginal input. ${ }^{11}$

The factor land is immobile by its very nature. Depending on the (political) regime, labor may be immobile ('trade regime') or mobile ('geography regime'). This differentiation allows us to tie up our analysis both with Krugman's (1980) work on international trade as well as with the more recent new economic geography started by Krugman (1991). To work out the role of land as a productive factor in its sharpest form, we start out by making the extreme assumption that labor uses no space for housing.

\footnotetext{
${ }^{10}$ This non-homotheticity assumption can be traced back to Lawrence and Spiller (1983), Flam and Helpman (1987) and Forslid and Ottaviano (2003) in trade and new economic geography models, respectively.

${ }^{11}$ We have also studied an alternative version of the model in which we have reversed the roles of land and labor. This yielded similar results implying that our overal conclusions are robust.
} 


\subsection{Preferences and demand}

Preferences of consumers in region $i=1,2$ are of the CES-type:

$$
U_{i}=\left(\int_{0}^{n_{i}} m_{i i}(v)^{\frac{\sigma-1}{\sigma}} \mathrm{d} v+\int_{0}^{n_{j}} m_{j i}(v)^{\frac{\sigma-1}{\sigma}} \mathrm{d} v\right)^{\frac{\sigma}{\sigma-1}}
$$

where $m_{j i}(v)$ is region $i$ 's consumption of variety $v$ produced in region $j, n_{i}$ is the total number (mass) of varieties in region $i$, and $\sigma>1$ is the elasticity of substitution between any two varieties. The budget constraint of region $i$ with regional income $Y_{i}$ is given by

$$
Y_{i}=\int_{0}^{n_{i}} p_{i}(v) m_{i i}(v) \mathrm{d} v+\int_{0}^{n_{j}} p_{j}(v) m_{j i}(v) \mathrm{d} v
$$

where $p_{i}(v)$ denotes the consumer price of variety $v$ in region $i$. Standard utility maximization yields the demand functions:

$$
\begin{gathered}
m_{j i}(v)=p_{j}(v)^{-\sigma} G_{i}^{\sigma-1} Y_{i} \\
\text { where } G_{i}=\left(\int_{0}^{n_{i}} p_{i}(v)^{1-\sigma} \mathrm{d} v+\int_{0}^{n_{j}} p_{j}(v)^{1-\sigma} \mathrm{d} v\right)^{\frac{1}{1-\sigma}}
\end{gathered}
$$

is the CES price index associated with (1). The indirect utility $V_{i}$ that each individual derives in region $i$ is then given by:

$$
V_{i}=\frac{Y_{i} / L_{i}}{G_{i}}
$$

where $Y_{i}$ is regional income which consists of wages and land rent:

$$
Y_{i}=w_{i} L_{i}+\left(r_{i} S_{i}+r_{j} S_{j}\right) \frac{L_{i}}{L_{i}+L_{j}}
$$

The wage in region $i$ is denoted by $w_{i}$, the price of a unit of land is denoted by $r_{i}$ and $L_{i}$ and $S_{i}$ denote the endowments of labor and land, respectively. We follow Helpman (1998) in assuming that the total amount of land in the economy is equally owned by individuals. Hence, the land rent accruing to region $i$ is proportional to its share of total labor.

\subsection{Production}

The industry is characterized by monopolistic competition and iceberg trade costs. Each variety is produced by a single firm under increasing returns to scale with a non-homothetic 
technology. $F$ units of labor are needed as an essential fixed input and one unit of output is then produced with $c$ units of land. Total costs of a firm which produces variety $v$ are $w_{i} F+r_{i} c q_{i}(v)$ where $q_{i}(v)$ is the output of this firm. Iceberg trade costs apply for imported goods: only $1 / \tau$ of a unit bought in the other region are available for consumption, with $\tau \geq 1$. Indicating producer prices by a hat, we have $p_{i}(v)=\hat{p}_{i}(v)$ in the region where the variety is produced and $p_{j}(v)=\tau \hat{p}_{j}(v)$ in the other region $(j=1,2$ and $i \neq j)$. With $q_{i}(v)$ denoting the total output of firm $v$, the market clearing condition is given by

$$
q_{i}(v)=m_{i i}(v)+\tau m_{i j}(v)
$$

where we have taken into account that part of the goods melt when shipped to foreign consumers. It is well-known that in the Dixit-Stiglitz model of monopolistic competition mill pricing is optimal for firms. Accordingly, profits of firm $v$ in region $i$ can be written as

$$
\pi_{i}(v)=\left(\hat{p}_{i}(v)-c r_{i}\right) q_{i}(v)-w_{i} F
$$

The maximization of profits (8) given (7) under the Chamberlinian large group assumption implies that optimal producers prices are constant markups on marginal costs:

$$
\hat{p}_{i}(v)=\frac{\sigma}{\sigma-1} c r_{i}
$$

Profits are zero in the long-run equilibrium that we consider. Hence, from (8) operating profits are fully absorbed by the wages of the skilled, so that:

$$
w_{i}=\frac{\hat{p}_{i}(v) q_{i}(v)}{\sigma F}
$$

The firms in the industry are perfectly symmetric allowing us to suppress the index $v$ henceforth. The number of firms in each region follows from the labor market clearing condition which can then be written as

$$
n_{i}=L_{i} / F
$$

and the equilibrium in the land market commands $S_{i}=c n_{i} q_{i}$, which using $q_{i}$ from (10), $\hat{p}_{i}$ from (9) and $n_{i}$ from (11) can be rewritten as:

$$
w_{i}=\frac{S_{i}}{L_{i}(\sigma-1)} r_{i}
$$


We choose land in region $i=1$ as the numéraire. Hence $r_{1}=1$ and all prices are expressed in terms of this numéraire.

Combining (9), (10) and (12) we can immediately conclude that firm $i$ 's output is tied to the land-labor ratio and the parameters of fixed and variable costs:

$$
q_{i}=\frac{S_{i}}{L_{i}} \frac{F}{c}
$$

From an inspection of (10) given the output (13) it follows that the operating surplus of firms, $\hat{p}_{i} q_{i} / \sigma$, and hence, the wage which accrues to labor, depends on mill prices and, hence, by (9) on the land rent.

\section{$4 \quad$ Trade}

The equilibrium. Labor is immobile, unable to move across national borders in the trade regime that we consider first. The equilibrium of the model described by eqs. (1) - (13) is derived as follows. With $L_{1}$ and $L_{2}$ exogenous in the trade regime, the number of firms in the two regions is fixed by (11) and so is their output by (13). Moreover, given $r_{1}=1$, the wage in region 1 is immediately implied by (12), $w_{1}=S_{1} / L_{1}(\sigma-1)$ and region 1 firm's mill prices are $\hat{p}_{1}=c \sigma /(\sigma-1)$ by (9). To obtain the equilibrium values of the other variables, the equilibrium return to land in region 2 has to be derived. Substituting total output (7), demand functions (3), mill prices (9) and regional incomes (6) in (10), using land market clearing (12) to substitute out for $w_{1}$ and $w_{2}$, labor market clearing (11) to substitute for the number of firms and setting $r_{1}=1$, we obtain the following equation in $r_{2}$ :

$$
\frac{\sigma S_{1}}{(\sigma-1) L_{1}}=\frac{\frac{S_{1}}{\sigma-1}+\left(S_{1}+r_{2} S_{2}\right) \frac{L_{1}}{L_{1}+L_{2}}}{L_{1}+\phi L_{2} r_{2}^{1-\sigma}}+\frac{\phi\left[\frac{r_{2} S_{2}}{\sigma-1}+\left(S_{1}+r_{2} S_{2}\right) \frac{L_{2}}{L_{1}+L_{2}}\right]}{\phi L_{1}+L_{2} r_{2}{ }^{1-\sigma}}
$$

Lemma 1. The model has a unique solution for the return to land in region 2, $r_{2}$, which is implicitly determined by eq. (14).

Proof. The proof is straightforward. The expression on the right hand side (RHS) in (14) approaches zero when $r_{2} \rightarrow 0$, and approaches $\infty$ when $r_{2} \rightarrow \infty$. Because the two numerators of the RHS in (14) are increasing in $r_{2}$ and the two denominators of the RHS are decreasing in $r_{2}$, the RHS is always increasing in $r_{2}$. 
From lemma 1 we know that the model has a unique solution in $r_{2}$. Given this solution, the other variables can be now derived in a straightforward manner. Region 2's wage follows from (12) and its mill prices from (9). The two regions' price indices and incomes can then be derived from (4) and (6). The individual demand and indirect utilities follow from (3) and (5), respectively. An important implication of lemma 1 is that the implicit function theorem can be used to derive the response of $r_{2}$ with respect to the exogenous parameters of the model. We make use of this result below.

Relative wages. Does the larger region have higher wages when land is used for production? To explore this question we use the two land market clearing conditions (12) and $1 / r_{2}=\hat{p}_{1} / \hat{p}_{2}$ which follows from (9) to obtain

$$
\frac{w_{1}}{w_{2}}=\frac{S_{1}}{S_{2}} \frac{L_{2}}{L_{1}} \frac{1}{r_{2}}=\frac{S_{1} / L_{1}}{S_{2} / L_{2}} \cdot \frac{\hat{p}_{1}}{\hat{p}_{2}}
$$

which shows that the relative wage is directly affected by the relative factor endowment of the two countries and by the relative producer prices (region 1's terms of trade).

To study the effect of differences in population size on the relative wage of the two countries, we assume that they are equally endowed with land, $S_{1}=S_{2}=S$. Moreover, from now on we impose the normalization $L_{1}+L_{2}=1$ and we use $\lambda$ to indicate the share of labor in region 1 , for convenience. It is a straightforward excercise to show that the response of the wage differential in (15) with respect to a marginal change in $\lambda$ at the symmetric equilibrium $(\lambda=1 / 2)$ is negative for $\sigma>\bar{\sigma} \equiv(3-\phi) / 2$ and positive otherwise. ${ }^{12}$

However, the result that the larger region may have the lower wage extends beyond local analysis and holds true for a wide range of $\lambda$ and $\phi$. Too see this, observe that by (15), the wage differential is a function of $r_{2}$ which itself is uniquely determined by eq. (14). However, because $r_{2}$ cannot be solved explicitly, we instead solve the condition $w_{1}=w_{2}$ for $r_{2}$ from (15), yielding $r_{2}=(1 / \lambda)-1$, and plug this into (14). This implies $\operatorname{sgn}\left(w_{1}-w_{2}\right)=$ $\operatorname{sgn}\left(\lambda^{3-2 \sigma}-(1-\lambda)^{3-2 \sigma}-\lambda^{1-\sigma}(1-\lambda)^{1-\sigma}(2 \lambda-1) \phi\right)$ for $\lambda \in(1 / 2,1]$. Because this has a unique solution $\lambda=\bar{\lambda}$, we can sign the wage difference as follows:

\footnotetext{
${ }^{12}$ This derivation makes use of the response of $r_{2}$ with respect to $\lambda$ at $\lambda=1 / 2$ that can be derived by implicit differentiation of eq. (14).
} 
Lemma 2. If $\sigma<\bar{\sigma}$ and $1 / 2<\lambda<\bar{\lambda}$, then $w_{1}>w_{2}$ holds, where $\bar{\sigma}=(3-\phi) / 2$ and $\bar{\lambda}$ is the unique solution of $\lambda^{3-2 \sigma}-(1-\lambda)^{3-2 \sigma}-\lambda^{1-\sigma}(1-\lambda)^{1-\sigma}(2 \lambda-1) \phi=0$ in $\lambda \in(1 / 2,1]$

Proof. See appendix A.

Lemma 2 suggests that the wage is higher in a larger region only if (I) $\sigma<\bar{\sigma}$ and (II) $1 / 2<\lambda<\bar{\lambda}$, where $\bar{\lambda}$ is the unique solution of (16). Condition (I) holds for small $\sigma$ and for large $\bar{\sigma}$. With $\bar{\sigma}$ decreasing in $\phi$ the wage is higher in a larger region for small $\sigma$ and $\phi$. Condition (II) holds for large $\bar{\lambda}$. Since $\bar{\lambda}$ is decreasing in $\phi$ (see appendix A) condition (II) is fulfilled for small $\phi$. Putting the two conditions, the wage is likely to be higher in a larger region when the trade freeness is low and goods are differentiated. We have thus proven:

Proposition 1. The wage is higher in a larger region only if trade is very costly ( $\phi$ small), goods are bad substitutes ( $\sigma$ small), and the labor size does not differ much ( $\lambda$ close to $1 / 2$ ). Otherwise, the wage is lower in a larger region.

This proposition is noteworthy because it implies that an important feature of Krugman's (1980) model - namely, the larger country having the larger wage - does not generally hold true when production uses land. Moreover, lemma 2 implies that this result holds true not only locally but for a wide range of $\lambda$ and $\phi$.

Proposition 1 can be understood intuitively by noting that the two forces determining the relative wage in (15) move in opposite directions when labor is shifted from region 2 to region 1 . The change in relative factor proportions $\left(S_{1} / L_{1}\right) /\left(S_{2} / L_{2}\right)$ exerts an unambiguously negative effect on the relative wage. This effect is independent of trade costs and the elasticity of substitution. The induced change in relative producer prices (region 1's terms of trade), $1 / r_{2}=\hat{p}_{1} / \hat{p}_{2}$, on the other hand, is positive and depends on the parameter values of trade costs and the elasticity of substitution since $r_{2}$ is determined by (14). This positive response derives from the fact that shifting labor from region 2 to region 1 makes land more (less) abundant in region 2 (region 1) thus decreasing (increasing) the return to land in region 2 (1), and hence increasing the relative producer price. The reason for the discrepancy of our results with those obtained by Krugman (1980) is now immediate. He considers a model where labor is the only production factor so that only a terms-of-trade effect obtains whereas in our model, which includes a second, immobile, productive factor, there is also a factor proportions effect 
which works in the opposite direction to the terms-of-trade effect and counteracts the first one when $\sigma$ is large enough.

\section{Geography}

\subsection{Market equilibrium}

Spatial equilibrium and adjustment process. This section explores the market equilibrium in the geography regime where labor is mobile. A spatial equilibrium arises at $\lambda \in(0,1)$ when

$$
\Delta V(\lambda) \equiv V_{1}(\lambda)-V_{2}(\lambda)=0
$$

or at $\lambda=0$ when $\Delta V(0) \leq 0$ or at $\lambda=1$ when $\Delta V(1) \geq 0$. Following Fujita et al. (1999), we assume that the adjustment process is governed by the standard myopic ad hoc dynamic equation

$$
\frac{d \lambda}{d t}=\Delta V(\lambda) \cdot \lambda \cdot(1-\lambda)
$$

so that the share of labor in region 1 increases when labor realizes higher utility in region 1 than in region 2. An equilibrium is locally stable if, given any marginal deviation of the distribution of labor from this equilibrium, the equation of motion specified in (17) implies that the labor distribution is brought back to this equilibrium. Note that with immobile land as a production factor, the analysis of geography (mobile labor) becomes meaningful unlike in the Krugman (1980) model where, due to the terms-of-trade effect, all labor would (trivially) always agglomerate in one location. In our model the following holds true:

Proposition 2. There exists a stable interior equilibrium for all parameter values.

Proof. See appendix B

This proposition guarantees the existence of at least one stable and interior equilibrium, say $\lambda *$, which equalizes the indirect utilities of the mobile agents, such that $\Delta V\left(\lambda^{*}\right)=0$, for all parameter values, i.e. even for countries which are asymmetric with respect to their endowments of land. Note, however, that there may exist multiple stable equilibria.

Symmetry breaking. Because the focus of our analysis is on the symmetric case, we assume that the two countries are ex-ante equal, $S_{1}=S_{2}$ from now on. Symmetry $(\lambda=1 / 2)$ is always an equilibrium. However, this equilibrium need not be stable since the model contains 
agglomeration forces. Performing the standard analysis of symmetry-breaking, i.e. setting the derivative of the utility differential (5) equal to zero, $d \Delta V(\lambda) /\left.d \lambda\right|_{\lambda=1 / 2}=0$, and solving for the degree of trade freeness, $\phi$, we obtain:

$$
\phi_{1 / 2}=\frac{\sigma(3-\sigma)-1 \pm \sqrt{1-4 \sigma(\sigma-1)(\sigma-2)}}{\sigma(\sigma+1)}
$$

Real and meaningful solutions of (18) require that the term in the square root is positive which is the case for $\sigma<2.11$. For $\sigma \geq 2.11$, the symmetric equilibrium does not break. Evaluating the third derivative of the RHS of (17) with respect to $\lambda$ at these roots, yields expressions which are always negative numerically. This implies that the bifurcations are of the supercritical type (Grandmont 1988). Eq. (18) reveals that these bifurcation points are fully characterized by the freeness of trade, $\phi$, and the elasticity of substitution, $\sigma$. A graphical exposition of the bifurcation points is provided by the solid line in figure 1. An asterisk $\left(^{*}\right)$ is used to indicate the stable spatial equilibria (ignore the dashed line and the symbol $\lambda^{o}$ which indicates the second-best optima until the next paragraph).

\section{[figure 1 about here]}

The results portrayed by the solid curve imply that the bifurcation pattern of the model is parameter-dependent. The range of the substitution parameter where symmetry breaking occurs is narrow: unless $\sigma$ is small, there is full dispersion (i.e. above the solid curve). For the interval $\sigma \in(2,2.11)$ both a break point and a redispersion point exist implying a bellshaped bifurcation diagram with 'smooth' agglomeration and deglomeration processes starting at $\phi_{1}$ and ending at $\phi_{2}$. For values of $\sigma$ below this interval only a redispersion point exists, but no break point. Hence, there is full dispersion at low trade costs and when trade costs are increased there are increasing degrees of (partial) agglomeration resembling the location pattern that emerges when land is used for housing (Helpman 1998). Interestingly, an inspection of figure 1 shows that for values of $\phi>0.13$, the relationship between the symmetry breaking level of trade freeness and the substitution parameter $\sigma$ is negative, in contrast to the usual finding (Krugman 1991). The results of this section are summarized in

Proposition 3. ('Substantial market power is needed for agglomeration to occur at all'). (i) For values of $\sigma$ exceeding 2.11, the model features dispersion for all levels of trade freeness. 
(ii) In the interval $\sigma \in(2,2.11)$, a break point and a redispersion exist as given by (17). (iii) For values of $\sigma$ below 2, the model has a redispersion point only.

Agglomeration and dispersion forces. The essence of proposition 3 is that the elasticity of substitution has to be small and hence market power of firms has to be large for agglomeration to occur. To gain some intuitive understanding of this result it is useful to perform an analytical decomposition of the symmetry breaking condition into the basic locational forces that are at work in the model: two agglomeration forces and two dispersion forces. The analytical expressions of these forces are provided in appendix $\mathrm{C}$, here we discuss their economic meaning. Start at the symmetric equilibrium and consider the relocation of a small mass of mobile labor from region 2 to region 1. This relocation affects indirect utilities through its impacts on price indices and wages. ${ }^{13}$ For given wages (incomes) the impacts on price indices are twofold. First, there is a supply linkage which acts as an agglomeration force: the relocation of labor induces a fall in region 1's price level because the range of goods available without trade costs expands. Hence the indirect utility in region 1 increases (vice versa for region 2). Second, there is also a competition effect in the factor market which acts as a dispersion force: the relocation of labor raises the cost of land and, hence, the producer prices in region 1 whilst an inverse effect is observed in region 2; this amelioration of region 1's terms-of-trade raises the price of locally consumed goods relative to imported goods, thus raising the price level in region 1 and lowering the indirect utility (vice versa for region 2). The other two forces work through wages, taking price levels as given. The third force is a demand linkage, an agglomerative force: the relocation of labor increases region 1's market size and, hence, the operating profits of firms, which accrue as wages (quasi-rents) to mobile labor. This effect raises the indirect utility in region 1 (vice versa for region 2). However, there is also a dampening effect on wages through more intense competition (crowding) on the product market: the relocation of labor induces a fall in region 1's price level, which (by (3), (7), (9) and (10)) reduces the demand for each variety and firm's operating profit and the wage that accrues to mobile labor. Note that this product market competition (or crowding) effect which is commonly observed in the new economic geography literature, is magnified in our setting: the relocation of labor to region 1 raises producer prices of region 1 relative to region 2 (the terms-of-trade effect) which reinforces the fall in the demand for each variety.

\footnotetext{
${ }^{13}$ Note that an individual's indirect utility depends on the price level and on her income (see (5)) which, by (6), consists of the wage and the land rent. Under our assumption that each individual owns an equal share of the total endowment of land, her land rent is unaffected by the relocation of a small mass of mobile labor (see appendix B). Hence, the effect on income derives from the impact on the wage, only.
} 
This exercise entails several insights. First, when land-use for production is taken into account, the set of location forces that is commonly observed in new economic geography models is modified in two ways: first, in addition to the usual supply linkage, demand linkage and (product) market competition effect (e.g. Krugman 1991), there is now also a factor market competition effect. Moreover, the dispersive force of the product market competition effect is reinforced as just explained. Second, adding up the demand linkage and the product market competition effect (see the analytical expressions in appendix C), the combined effect is acting in favor of agglomeration for $\sigma<\bar{\sigma}=(3-\phi) / 2$ and against agglomeration for $\sigma>\bar{\sigma}$ which is in coherence with proposition 1. Third, agglomeration is inhibited by the two competition effects unless the degree of substitution is small enough. Moreover, simulations for the interval $\sigma \in(2,2.11)$ reveal that the competition effects on the product and the factor markets dominate the two agglomeration forces, when trade freeness is very low and when it is very high, rationalizing part (ii) of proposition 3. Hence, our model comprehends the case of a bell-shaped agglomeration process without imposing the assumption of a class of immobile labor ('farmers'). ${ }^{14}$

Relative wages. It remains to characterize the behavior of relative wages in a stable equilibrium. We stick to ex ante identical regions and start by noting

Lemma 3. If $\lambda^{*}>1 / 2$ is a stable equilibrium under $S_{1}=S_{2}$, then $r_{2}<r_{1}=1$.

\section{Proof. See appendix D}

Lemma 3 carries the message that when an asymmetric distribution is a stable equilibrium, the land rent in the large region is always higher than that in the small region. This is because land is scarcer in the region with more labor agglomeration. This leads us immediately to

Proposition 4. If $\lambda^{*}>1 / 2$ is a stable equilibrium under $S_{1}=S_{2}$, then $w_{1}<w_{2}$.

Proof. See appendix E. Note that this appendix applies to proposition 5 which covers a more general setting that we present in the next section. Proposition 4 is a corollary to proposition 5 which is obtained by setting $\alpha=0$

\footnotetext{
${ }^{14}$ Most of the works which imply a bell-shaped bifurcation pattern (e.g. Puga 1999; Tabuchi and Thisse 2002a; Pflüger and Südekum 2008) assume the existence of a class of immobile 'farmers' which gives rise to the 'competition effect' which (under a standard no-black-hole condition) is the dominant location force at high trade costs. One exception is Murata (2003) who integrates taste heterogeneity concerning locations into a new economic geography model without immobile farmers.
} 
According to this proposition whenever an asymmetric distribution is a stable equilibrium, the wage in the region with the higher share of labor and firms is always lower than the wage in the (partial) periphery. Intuitively, this is so because labor is the relatively abundant factor in the large region. Interestingly, in the geography regime (i.e. with mobile labor) the larger region always has the lower wage in a stable equilibrium, whereas with immobile labor (the trade regime) this was only the case for $\sigma>\bar{\sigma}{ }^{15}$

\subsection{The social optimum}

We now turn to explore the efficiency of the spatial equilibria given the prevailing market structure, i.e. monopolistic competition in the production of differentiated goods and services, and assuming that the two regions are equally endowed with land, $S_{1}=S_{2}=S$. Specifically, we ask whether labor can be reallocated across locations with the (potential) winners compensating the (potential) losers such that the welfare of all individuals is raised. Such a second-best optimum can be implemented through a lump-sum tax-transfer mechanism across the two regions where the national government (a 'benevolent social planner') transfers lump sum income $T$ from region 2 to region 1 to equalize indirect utilities and then chooses the allocation of labor $(\lambda)$ to maximize the (common) level of indirect utility. ${ }^{16}$

With such a tax-transfer system regional incomes are given by:

$$
Y_{1}=w_{1} L_{1}+S\left(1+r_{2}\right) \lambda+T \quad \text { and } \quad Y_{2}=w_{2} L_{2}+S\left(1+r_{2}\right)(1-\lambda)-T
$$

Since the implied utility differential $\Delta V$ is linear in the transfer, $\Delta V=0$ can easily be solved for $T$. Call the solution $\hat{T}$. Moreover, define $\hat{V}_{1}\left(\lambda, r_{2}\right)$ to be $V_{1}$ with $T=\hat{T}$ and let $\hat{\mathrm{g}}\left(\lambda, r_{2}\right)=0$ be the counterpart to eq. (14) with regional incomes given by (19) instead of (6) and with the transfer given by $T=\hat{T}$. The implicit function $\hat{\mathrm{g}}\left(\lambda, r_{2}\right)=0$ defines the return to land in region $2, r_{2}$, for any given $\lambda$ and the primitives of the model. Then, the second-best social optimum is obtained from:

$$
\max _{\lambda} \hat{V}_{1}\left(\lambda, r_{2}\right) \quad \text { subject to } \quad \hat{\mathrm{g}}\left(\lambda, r_{2}\right)=0
$$

One obvious candidate for the maximizer is $\left(\lambda, r_{2}, T\right)=(1 / 2,1,0)$ which generates the full dispersion of manufacturing activities. In fact, it can readily be shown that

\footnotetext{
${ }^{15}$ These different results can be explained as follows. It is true from proposition 1 that a small migration leads to $w_{1}>w_{2}$ when $\sigma<\bar{\sigma}$. However, we know from (18) that when $\sigma<\bar{\sigma}$, the symmetric equilibrium is not stable under free migration of labor. That is, $w_{1}>w_{2}$ never happens in stable equilibrium.

${ }^{16}$ Note that such a compensation scheme encompasses potential Pareto-improvements, too.
} 


$$
\begin{aligned}
& \left.\frac{\mathrm{d} \hat{V}_{1}}{\mathrm{~d} \lambda}\right|_{\left(\lambda, r_{2}\right)=(1 / 2,1)}=\frac{\partial \hat{V}_{1}}{\partial \lambda}+\left.\frac{\partial \hat{V}_{1}}{\partial r_{2}}\left(-\frac{\partial \hat{g} / \partial \lambda}{\partial \hat{g} / \partial r_{2}}\right)\right|_{\left(\lambda, r_{2}\right)=(1 / 2,1)}=0 \\
& \left.\frac{\mathrm{d}^{2} \hat{V}_{1}}{\mathrm{~d} \lambda^{2}}\right|_{\left(\lambda, r_{2}\right)=(1 / 2,1)}=-\frac{(1+\phi)^{\frac{1}{\sigma-1}}[2-\sigma(1-\phi)]^{2} S}{(2 F)^{\frac{1}{\sigma-1}}(\sigma-1)^{2} c \phi \sigma}<0
\end{aligned}
$$

implying that $\left(\lambda, r_{2}, T\right)=(1 / 2,1,0)$ is indeed a local maximizer of $\hat{V}_{1}$. However, full dispersion is not necessarily a global maximizer since $\hat{V}_{1}$ is, in general, not quasi-concave. Moreover, identifying the global maximizer for the social optimum problem (20) turns out to be analytically intractable. Hence, we resort to numerical analysis in order to determine the second-best socially optimal allocations for alternative values of $(\phi, \sigma)$. In particular, a threshold curve can be computed numerically and depicted in dashed form in $\phi-\sigma$-space of figure 1 such that above this threshold, full dispersion is socially optimal, whilst below it partial agglomeration is socially optimal. The socially optimal allocations of labor are indicated by $\lambda^{o}$.

Figure 1 juxtaposes this threshold curve with the solid symmetry breaking curve that we obtained for the market equilibrium. Our simulations reveal that the dashed threshold curve is always below the symmetry breaking curve except at zero trade freeness $(\phi=0)$ and at full trade freeness $(\phi=1)$. Three domains are delimited by these two curves. Above the solid curve, i.e. if both $\phi$ and $\sigma$ are large, both the market outcome and the second-best optimum involve full dispersion $\left(\lambda^{*}=\lambda^{o}=1 / 2\right)$. In the domain between the solid and the dashed curve, i.e. for intermediate values of $\phi$ and $\sigma$, the social optimum is full dispersion whereas the market equilibrium is partial agglomeration. Hence, in this domain, the market outcome provides excessive agglomeration $\left(\lambda^{*}>\lambda^{o}=1 / 2\right.$, where, due to symmetry; the transfer is nil, i.e. $\left.\hat{T}^{o}=0\right)$. Moreover, even though both the market outcome and the second-best social optimum involve partial agglomeration below the dashed curve, i.e. for small values of $\phi$ and $\sigma$, the market outcome again provides excessive agglomeration $\left(\lambda^{*}>\lambda^{o}>1 / 2\right)$. The secondbest optimum now involves a lump-sum transfer from the larger region to the smaller region (i.e. $\left.T^{o}<0\right)$.

This result provides a striking contrast to Helpman (1998) who focuses on land-use for housing in a model with labor as the only factor of production. Even though land acts as a dispersive force in the cases of production and housing, our welfare analysis indicates that 
with land-use for production excessive agglomeration obtains, whereas Helpman finds that there is too little agglomeration. To explore this difference we contrast in figure 2 both for our model (upper panel) and for Helpman's (1998, figure 2.6) model (lower panel) the indirect utility curves that obtain when the symmetric equilibrium breaks, and asymmetric equilibria emerge as stable equilibria: ${ }^{17}$

\section{[figure 2 about here]}

In both panels the symmetric equilibrium (indicated by a white circle) is unstable since a move from $\lambda=1 / 2$ to the right (left) implies an increasing (decreasing) utility differential $V_{1}-V_{2}$. The stable asymmetric equilibria are characterized by black circles. A comparison of the two panels reveals that, around $\lambda=1 / 2$, the indirect utilities peak in our model, whereas they have a trough in Helpman's model. As a result, in our model the utility is higher at the symmetric equilibrium than at asymmetric stable equilibria (black circles), implying overagglomeration. In Helpman's model, on the other hand, the white circle is below the black ones, which implies under-agglomeration. The difference can be attributed to the fact that $V_{1}(\lambda)$ is decreasing for $\lambda>1 / 2$ in our model, whereas it is increasing in Helpman's model. The development of indirect utilities itself reflects the fact that due to the factor proportions effect (absent in Helpman's model) an increase in $\lambda$ exerts a negative effect on the wage in our model. In the Helpman model, on the other hand, an increase in $\lambda$ raises the wage due to the land for housing constraint (absent in our model). It should also be noted that the indirect utility remains concave for the larger region for $\lambda>1 / 2$ (observe the behavior of $V_{1}$ ) whereas it changes from concave to convex in the smaller region (observe the behavior of $V_{2}$ ) in our model. In fact $V_{2}$ goes to infinity as $\lambda \rightarrow 1$, while $V_{1}$ remains finite. However, even though the utility of a few individuals who end up living in the periphery would be much higher by shifting the allocation of $\lambda$ beyond the rightmost equilibrium (equivalently: below the leftmost equilibrium), the tax that would be needed to compensate the other individuals is too high to make all of them better off. We return to this issue at the end of the next paragraph.

\footnotetext{
${ }^{17}$ Qualitatively similar curves are obtained for other sets of parameters.
} 


\section{Accounting for the facts}

\subsection{Equilibrium with land-use for production and housing}

The previous analysis shows that a number of central tenets of the new trade theory and the new economic geography cease to hold when land-use for productive purposes is taken into account. However, these surprising results come at the cost that our model, even though correctly reflecting the factual dominance of land-use for production, is at odds with the empirical facts that larger locations have higher (nominal) wages and that the cost of living is higher in larger locations (cf. section 1). We show in this section that our model can be reconciled with these facts by simply assuming that land is not only used for production but for housing, too. All other implications remain unchanged. Let us point out that this modification is clearly only one possible way to address these two facts. Productivity advantages deriving from knowledge spillovers, for example, would clearly be another explanation. We focus on land-use for housing in addition to production because this fits in nicely with the factual use of land that we have documented in the introduction and because this appears to be the most parsimonious way to explain the facts. We return to this issue below, however.

The model with land-use for production and housing. To include land for housing we follow Helpman (1998) and assume that preferences in region $i$ are of the Cobb-Douglas cum CEStype: ${ }^{18}$

$$
U_{i}=\frac{1}{\alpha^{\alpha}(1-\alpha)^{1-\alpha}} h_{i}^{\alpha} m_{i}^{1-\alpha}, \quad m_{i}=\left(\int_{0}^{n_{i}} m_{i i}(v)^{\frac{\sigma-1}{\sigma}} \mathrm{d} v+\int_{0}^{n_{j}} m_{j i}(v)^{\frac{\sigma-1}{\sigma}} \mathrm{d} v\right)^{\frac{\sigma}{\sigma-1}}
$$

with $0 \leq \alpha \leq 1$, where $h_{i}$ represents region $i$ 's consumption of land for housing, and $m_{i}$ is now the CES subutility over differentiated products. The budget constraint of region $i$ is now given by:

$$
Y_{i}=r_{i} h_{i}+\int_{0}^{n_{i}} p_{i}(v) m_{i i}(v) \mathrm{d} v+\int_{0}^{n_{j}} p_{j}(v) m_{j i}(v) \mathrm{d} v
$$

Standard utility maximization yields the demand functions:

\footnotetext{
${ }^{18}$ This way of integrating housing into our model is a short-cut which we follow for simplicity. Taking an urban spatial structure into account would involve considering commuting costs between housing and production sites and shipping costs from firm sites to a marketplace in a region, which is beyond the scope of this paper.
} 


$$
h_{i}=\frac{\alpha Y_{i}}{r_{i}}, \quad m_{i}=\frac{(1-\alpha) Y_{i}}{G_{i}} \quad m_{j i}(v)=(1-\alpha) p_{j}(v)^{-\sigma} G_{i}^{\sigma-1} Y_{i}
$$

where $G_{i}$ is the price index as defined in eq. (4). The indirect utility $V_{i}$ that each individual derives in region $i$ reflects the Cobb-Douglas price index $r_{i}{ }^{\alpha} G_{i}{ }^{1-\alpha}$ in the denominator

$$
V_{i}=\frac{Y_{i} / L_{i}}{r_{i}^{\alpha} G_{i}^{1-\alpha}}
$$

with income given by eq. (21). We retain the assumption that the total amount of land in the economy is equally owned by individuals. Hence eq. (6) continues to apply. The production side of the economy is as described before in eqs. (7) through (11). However, equilibrium in the land market now commands $S_{i}=c n_{i} q_{i}+h_{i}$ because land is used for production and housing. Substituting $q_{i}$ from (10), $\hat{p}_{i}$ from (9), $n_{i}$ from (11) and $h_{i}$ from (22) land market clearing can be rewritten as:

$$
S_{i}=\frac{w_{i}}{r_{i}} L_{i}(\sigma-1)+\frac{\alpha Y_{i}}{r_{i}}
$$

where land in region $i=1$ is again chosen as the numéraire, hence $r_{1}=1$.

Equilibrium and relative wages under trade. The derivation of the trade equilibrium (i.e. with labor being immobile internationally) is conceptionally similar albeit a little bit more involved than before. Note that, given $r_{2}$, eqs. (24) and (6) (for $i=1,2$ ) form a simultaneous equation system which can be solved for $w_{i}\left(r_{2}\right)$ and $Y_{i}\left(r_{2}\right)$. Moreover, substituting the expressions for total output (7), demand functions (22), mill prices (9) and the number of firms (11) into eq. (10), we obtain $w_{1}=\frac{1}{\sigma}\left[\frac{(1-\alpha) Y_{1}}{\lambda+\phi(1-\lambda) r_{2}^{1-\sigma}}+\frac{\phi(1-\alpha) Y_{2}}{\phi \lambda+(1-\lambda) r_{2}^{1-\sigma}}\right]$ which, on substituting $w_{1}\left(r_{2}\right)$ and $Y_{i}\left(r_{2}\right)$ provides an implicit equation for $r_{2}$, the counterpart of eq. (14). Similar arguments as before can be invoked to show that the modified model has a unique solution for the return to land, $r_{2}$, and that, increasing region 1's share of labor, $\lambda$, around a symmetric equilibrium, leads to an increase (decrease) in $w_{1} / w_{2}$ for $\sigma<\bar{\sigma}(\sigma>\bar{\sigma})$ where $\bar{\sigma} \equiv(3-\phi) / 2$, as before. Hence, in the trade regime, the model behaves as before.

Geography: existence of equilibrium and symmetry breaking. Turning to the geography regime and invoking similar arguments as before it can be verified that proposition 2, i.e. the 
existence of a stable spatial equilibrium for the geography regime holds with land-use for production and housing, too. Furthermore, we continue to assume that the adjustment of labor is governed by the dynamic equation (17). Making use of the indirect utilities (23) and performing the symmetry breaking analysis as before, the following bifurcation points obtain:

$$
\begin{aligned}
& \begin{array}{l}
\phi_{1,2}=\frac{\sigma(3-\sigma)-1+\alpha^{2}[\alpha+\sigma(2 \sigma-3)]+\alpha[1+\sigma(2 \sigma-1)] \pm \sqrt{Z}}{3\left\{\sigma^{2}(1-2 \alpha)^{2}+\sigma[1-2 \alpha(3 \alpha-2)]-(1-\alpha) \alpha\right\}} \\
\text { with } \quad \begin{aligned}
Z \equiv(2-\alpha-\sigma)(\alpha+\sigma-1)\left[3(\alpha-1) \alpha+\sigma-2 \alpha(3 \alpha-2) \sigma+(1-2 \alpha)^{2} \sigma^{2}\right] \\
+
\end{aligned} \\
\qquad\left[1+(\sigma-3) \sigma+\alpha^{2}(\sigma(3-2 \sigma)-2)+\alpha(1+\sigma(2 \sigma-1))\right]^{2}
\end{array}
\end{aligned}
$$

which reduces to (18) for $\alpha=0$. Even though an analytical solution can be provided for these bifurcation points which obtain with land-use both for production and housing, they are rather unrevealing. However, the bifurcation points are amenable to numerical analysis. As before, it is possible to depict the combinations of the parameters $\phi$ and $\sigma$ at which symmetry breaking occurs where we take the expenditure share devoted to housing, $\alpha$, as parametrically given now. Above this curve the market equilibrium involves dispersion, below it partial agglomeration obtains. Two cases have to be distinguished. For $\alpha<0.261$ the symmetry breaking curve has a hump for small values of $\phi$ and then slopes downward, similar to the threshold curve that obtained with land for production, only (the solid curve figure 1). This case where a low budget share is devoted to housing is depicted by the solid curve in the upper panel of figure $3(\alpha=0.2)$. For $\alpha \geq 0.261$ the symmetry breaking curve slopes downward. The solid curve in the lower panel of figure 3 depicts the case where $\alpha=0.4$.

\section{[Figure 3 about here]}

We can conclude that the behavior of the economy using land both for housing and production is qualitatively similar to the economy that we have described before as long as the budget share devoted to housing is low. When the budget share devoted to housing is high enough, the hump in the symmetry breaking curve vanishes, and, hence, the bell-shaped bifurcation no longer obtains.

Land use. The aggregate demand for land for housing is given by $\alpha Y_{i} / r_{i}$ according to eq. (22). Hence, the share of land-use for housing is given by $\alpha Y_{i} / r_{i} S_{i}$ (cf. eq. (24)). For the case of full dispersion, this share can be computed to be $\alpha \sigma /(\alpha+\sigma-1)$, which is zero when $\alpha=0$ 
and monotonically increases to 1 for $\alpha=1$. This simply means that as the preference for housing gets stronger, housing consumption goes up, and hence, land use for housing increases relative to land use for production.

Relative wages. How about relative wages, the critical issue? On the basis of a numerical analysis the following result which follows up on proposition 4 is readily shown:

Proposition 5: Suppose $\lambda^{*}>1 / 2$ is a stable equilibrium under $S_{1}=S_{2}$. Then, $w_{1}>w_{2}$ for $\alpha>1 / 2$, and $w_{1}<w_{2}$ for $\alpha<1 / 2$.

Proof. See appendix E.

Hence, if the budget share devoted to housing as expressed by $\alpha$ exceeds $50 \%$, then the wage in the larger region is higher. This result immediately entails:

Proposition 6: Suppose $\lambda^{*}>1 / 2$ is a stable equilibrium under $S_{1}=S_{2}$. Then, with $P_{i} \equiv r_{i}^{\alpha} G_{i}^{1-\alpha}, P_{1}>P_{2}$ for $\alpha>1 / 2$, and $P_{1}<P_{2}$ for $\alpha<1 / 2$.

Proof. In an interior equilibrium, $V_{1}=V_{2}$, so that $\left(Y_{1} / L_{1}\right) / P_{1}=\left(Y_{2} / L_{2}\right) / P_{2}$. Since $w_{1}>w_{2}$ $\left(w_{1}<w_{2}\right)$ implies $Y_{1} / L_{1}>Y_{2} / L_{2}\left(Y_{1} / L_{1}<Y_{2} / L_{2}\right)$, proposition 6 is immediately implied by proposition 5 .

Proposition 6 reveals that the region with the higher wage has the higher price level, too. The high wage is simply compensated by the high Cobb-Douglas price index which consists of land rent and the prices of differentiated varieties produced in the modern sector.

Hence, our model can be reconciled with the stylized facts when land-use for housing is included and once the budget share devoted to housing is high.

A remark on numbers. One important further observation concerns the numbers implied by our analysis. Both the model with land-use for production only and the modified model which also takes housing into account imply that the equilibrium involves full dispersion for rather low values of the elasticity of substitution - roughly in the range of 2 or even less. However, real-world estimates of mark-ups imply values for the elasticity of substitution in the range of 6 - 8 whilst agglomeration is in fact observed. Hence, although our (modified) model is qualitatively consistent with the facts on wages and prices there is an apparent discrepancy with real world numbers. Two remarks are in order here. First, this discrepancy is easily 
explained by the very stylized nature of our model, which, quite purposefully rules out any asymmetries between the two locations: full dispersion (i.e. an equal division of firms) would never arise in our model once we allowed for asymmetric land endowments, for example. A second and even deeper point that emerges from our analysis is that the market-size based agglomeration forces stressed in the new economic geography may simply not be strong enough to overcome the very strong congestion force associated with competition for land, unless the consumers desire for variety (which is expressed by a low value of the elasticty of substitution) is very strong. In turn this suggests, that further agglomeration forces such as e.g. knowledge spillovers must in addition be invoked in order to explain the agglomeration of economic activity that is observed in the real world.

\subsection{The social optimum}

It remains to characterize the second-best social optimum for the case where land is used both for production and housing. Following up on the tax-transfer compensation scheme that we introduced in section 5.2 and resorting to numerical analysis again, we are able to show the following. The threshold curve which delimits the combinations of $\phi$ and $\sigma$ which imply dispersion and partial agglomeration, respectively, is downward sloping even for a non-zero budget-share devoted to housing, $\alpha$. Moreover, the market symmetry breaking curve is always above the second-best social optimum so that there exists a lens-shaped domain between the two curves, where the social optimum is full dispersion, whereas the market outcome is asymmetric (partial) agglomeration. The market outcome then involves excessive agglomeration. Moreover, there is also excessive agglomeration below the dashed threshold for the social optimum. We can thus conclude that the results of the previous section (i.e. where $\alpha=0$ and land-use for housing was disregarded) carry over to the case with land-use for production and housing.

These results are illustrated in figure 3 where the dashed curves both in the upper and the lower panels are the threshold curves for the social optimum. Below the solid curve in each panel, there is market over-agglomeration. Very interestingly then, with land-use for production we always obtain a domain of parameters where market over-agglomeration is implied. In fact, the indirect utility with housing behaves similar to that without housing: near symmetry break it has a peak at around $\lambda=1 / 2$ as drawn in the upper panel of figure 2 . The discrepancy to the result obtained by Helpman (1998) that we have highlighted in section 5.2 thus carries over to the case with land-use for production and housing. Hence, the welfare 
implications of agglomeration models based on market-size effects and pecuniary externalities appear even be more fragile than previous works suggested (cf section 2).

\section{Conclusions}

This paper is motivated by the fact that, contrary to its importance in practice, the role of land for production has received (almost) no attention in the new trade theory and the new economic geography. We set up a simple monopolistic competition model to explore whether central tenets of that literature continue to hold when land-use for production is taken into account. Surprisingly, we find that the factor proportions effect which emerges when land and labor are used as productive factors indeed changes a number of previous results.

In particular, we show that, in contrast to the new trade literature, a larger country will have lower wages, in general. Allowing for labor mobility, we show that agglomeration is more likely to occur when the elasticity of substitution among varieties is small. The relationship between the level of trade freeness where symmetry is broken and the elasticity of substitution is inverse to the usual finding in the literature. In stark contrast to analyses where land is used for housing, only, the market equilibrium delivers excessive agglomeration in our model.

Our analysis also reveals, that in order to explain the stylised facts, notably that wages are higher in larger locations, land-use for production and housing has to be taken into account. The finding that the market-size based agglomeration forces are not strong enough to overcome the very strong congestion force associated with competition for land, unless the consumers desire of variety is very strong (as expressed by a low value of the elasticty of substitution) suggests that in order to explain the agglomeration of economic activity observed in the real world further agglomeration forces must be invoked.

\section{References}

Amiti, M. (1998), Inter-industry trade in manufactures: Does country size matter? Journal of International Economics 44: 231-255.

Amiti, M. (2005), Location of vertically linked industries: agglomeration versus comparative advantage. Journal of International Economics 49: 809-832.

Amity, M. and L. Cameron (2007), Economic geography and wages. Review of Economics and Statistics 89:1, 15-29.

Charlot, S., C. Gaigné, F. Robert-Nicoud, J.-F. Thisse (2006), Agglomeration and welfare: The core-periphery model in the light of Bentham, Kaldor, and Rawls, Journal of Public Economics 90, 325-347. 
Combes, P.P., G. Duranton, H.G. Overman (2005), Agglomeration and the adjustment of the spatial economy. Papers in Regional Science 311-349.

Davis, D. (1998), The home market, trade, and industrial structure. American Economic Review 88: 1264-1276.

Dixit, A. Stiglitz, J. (1977), Monopolistic competition and optimum product diversity. American Economic Review, 67: 297-308.

Flam, H., Helpman, E. (1987), Industrial policy under monopolistic competition. Journal of International Economics, 22: 79-102.

Forslid, R., Ottaviano, G. (2003), An analytically solvable core-periphery model. Journal of Economic Geography, 3: 229 - 240.

Fujita, M., Krugman, P., Venables, A. (1999), The spatial economy. Cities, regions, and international trade. Cambridge (Mass.): MIT Press.

Fujita, M., J.-F. Thisse (2002), Economics of agglomeration. Cities, industrial location and regional growth. Cambridge University Press: Cambridge.

Glaeser, E.L., D.C. Maré (2001), Cities and skills. Journal of Labor Economics 19:2, 316-342.

Gould, E.D. (2007), Cities, workers and wages: a structural analysis of the urban wage premium, Review of Economic Studies 74, 477-506.

Grandmont, J. (1988), Nonlinear Difference Equations, Bifurcations and Chaos: An Introduction. Lecture Notes No.5, IMSSS-Economics Lecture Notes Series, Institute for Mathematical Studies in the Social Sciences, Stanford, CA.

Head, K., T. Mayer (2004), The empirics of agglomeration and trade, in: J.V. Henderson and J.-F. Thisse (eds.), Handbook of Regional and Urban Economics: Cities and Geography. Volume 4. Amsterdam: Elsevier, 2609-2669.

Helpman, E. (1998) The size of regions, In: D. Pines, E. Sadka, I. Zilcha (eds.), Topics in public economics. Theoretical and empirical analysis. Cambridge University Press: $33-54$.

Helpman, E., P. R. Krugman (1985), Market Structure and Foreign Trade. The MIT-Press, Cambridge.

Holmes, T.J., J.J. Stevens (2005), Does home market size matter for the pattern of trade? Journal of International Economics 65: 489-505.

Ihara, R., (2005), Factor fistribution, capital intensity and spatial agglomeration. Annals of Regional Science 39, 107-120.

Krugman, P. (1979), Increasing returns, monopolistic competition, and international trade. Journal of International Economics 9, 469 - 479.

Krugman, P. (1980), Scale economies, product differentiation, and the pattern of trade. American Economic Review 70, 950-959.

Krugman, P. (1991), Increasing returns and economic geography. Journal of Political Economy, 99: 483-499.

Krugman, P., R.E. Livas Elizondo (1996), Trade policy and third world metropolis. Journal of Development Economics 49(1): 137-150.

Laussel, D., T. Paul (2007), Trade and the location of industries: some new results. Journal of International Economics 71: 148-166. 
Lawrence, C., P. Spiller (1983) Product diversity, economies of scale, and international trade. Quarterly Journal of Economics, 98: 63-83.

Murata, Y. (2003), Product diversity, taste heterogeneity, and geographic distribution of economic activities: market vs. non-market interactions. Journal of Urban Economics 53, 126-144.

Ottaviano, G.I.P., F. Robert-Nicoud (2006), The 'genome' of NEG models with vertical linkages: a positive and normative synthesis, Journal of Economic Geography 6: 113159.

Ottaviano, G.I.P., J.-F. Thisse (2002), Integration, agglomeration and the political economics of factor mobility, Journal of Public Economics 83, 429-456.

Ottaviano, G., J.-F. Thisse (2004), Agglomeration and economic geography. In V. Henderson and J.-F. Thisse (eds) Handbook of Regional and Urban Economics: Cities and Geography. Volume 4. Amsterdam: Elsevier, 2563-2608.

Ottaviano, G.I.P., T. Tabuchi, J.-F. Thisse (2002), Agglomeration and trade revisited, International Economic Review 43, 409-435.

Pflüger, M., J. Südekum, J. (2008), Integration, agglomeration and welfare. Journal of Urban Economics 63, 544-566.

Puga, D. (1999), The rise and fall of regional inequalities. European Economic Review, 43: 303-334.

Russek, S. (2008), Taste heterogeneity, labor mobility and economic geography - A critical reconsideration and correction, Economics Bulletin 18:1.

Südekum, J. (2006), Agglomeration and regional cost of living. Journal of Regional Science $46: 3,529-543$.

Tabuchi, T. (1998) Urban agglomeration and dispersion: a synthesis of Alonso and Krugman. Journal of Urban Economics, 44: 333-351.

Tabuchi, T., J.-F. Thisse (2002a), Taste heterogeneity, labor mobility and economic geography. Journal of Development Economics 69: 155-177.

Tabuchi, T., J.-F. Thisse (2002b), Regional specialization and transport costs, CEPR Discussion Paper 3542.

von Thünen, J.H. (1826), Der Isolierte Staat in Beziehung auf Landwirtschaft und Nationalökonomie. Hamburg: Perthes. English translation: The Isolated State. Oxford: Pergammon Press (1966).

Yankow, J.J. (2006), Why do cities pay more? An empirical examination of some competing theories of the urban wage premium. Journal of Urban Economics 60, 139-161. 


\section{Appendix A}

Proof of Lemma 2. Let $f(z)$ be the LHS of (16) by replacing $\lambda$ with $1 /(1+z)$ and dividing it by $z^{\sigma+1} /(1+z)^{3}$. Then, $f(z)=z^{2-\sigma}-z^{\sigma-1}+(1-z) \phi \quad$ where $z \in(0,1)$ because $\lambda=1 /(1+z) \in(1 / 2,1)$. It can be readily verified that $f^{\prime \prime}(z)=(2-\sigma)(\sigma-1)\left(z^{2 \sigma-3}-1\right) z^{-\sigma}>0$

since $1<\sigma<3 / 2$. Therefore, $f^{\prime}(z)$ is increasing. Because $\lim _{z \rightarrow 0} f^{\prime}(z)=-\infty$ and $f^{\prime}(1)=3-2 \sigma-\phi=2(\bar{\sigma}-\sigma)>0$, there exist a unique $z=\hat{z} \in(0,1)$ such that $f^{\prime}(z)<0$ for $1 / 2<z<\hat{z}$ and $f^{\prime}(z)>0$ for $\hat{z}<z \leq 1$. Therefore, $f(z)$ is first decreasing and then increasing. However, because $\lim _{z \rightarrow 0} f(z)=\phi$ and $f(1)=0$, there exist a unique $z=\bar{z} \equiv(1-\bar{\lambda}) / \bar{\lambda} \in(0,1)$ such that $f(z)>0$ for $1 / 2<z<\bar{z}$ and $f(z)<0$ for $\bar{z}<z \leq 1$. Thus, if $\sigma<\bar{\sigma}$ and $1 / 2<\lambda<\bar{\lambda}$, then $f(z)>0$, and hence, $w_{1}>w_{2}$ holds.

Proof that $\bar{\lambda}$ is decreasing in $\phi$. Because $\lim _{z \rightarrow 0} f(z)=\phi$ and $f(1)=0, f^{\prime}(z)$ at $z=\bar{z}$ is negative, where $\bar{z}$ is a unique solution of $f(z)=0$ in $(0,1)$. On the other hand, $\partial f(z) / \partial \phi>0$ holds. Applying the implicit function theorem to $f(z)=0$, we have

$$
\left.\frac{\mathrm{d} z}{\mathrm{~d} \phi}\right|_{f(z)=0}=-\left.\frac{\partial f(z) / \partial \phi}{f^{\prime}(z)}\right|_{f(z)=0}>0, \text { and hence, } \mathrm{d} \lambda /\left.\mathrm{d} \phi\right|_{f(z)=0}<0 .
$$

\section{Appendix B}

Proof of proposition 2. We first note that $\Delta V \equiv V_{1}-V_{2}$ is continuous for all $\lambda \in(0,1)$. This follows from the following argument. $\Delta V \equiv V_{1}-V_{2}=\frac{Y_{1} / L_{1}}{G_{1}}-\frac{Y_{2} / L_{2}}{G_{2}}$ is a function of $\lambda$ and $r_{2}$ because $Y_{1}, Y_{2}, G_{1}$ and $G_{2}$ are continuous functions of $\lambda$ and $r_{2}$. From lemma 1 we know that there exists a unique $r_{2}$ which solves eq. (14) given $\lambda$ and parameter values. Hence, we can rewrite eq. (14) as $r_{2}=r_{2}(\lambda)$. Then, $\Delta V\left(\lambda, r_{2}\right)=\Delta V\left(\lambda, r_{2}(\lambda)\right)$ as claimed. 
Given the continuity of $\Delta V \equiv V_{1}-V_{2}$ for all $\lambda \in(0,1)$, it is sufficient to show that $\lim _{\lambda \rightarrow 0} \Delta V>0>\lim _{\lambda \rightarrow 1} \Delta V$, so that there exists at least one solution $\lambda^{*}$ satisfying $\Delta V=0$ and $\mathrm{d} \Delta V /\left.\mathrm{d} \lambda\right|_{\lambda=\lambda^{*}}<0$.

In the case of $\lambda \rightarrow 0$, we readily have

$$
\lim _{\lambda \rightarrow 0} V_{2}=\frac{\sigma-1}{c \sigma}\left[\frac{1}{F}\right]^{\frac{1}{\sigma-1}}\left[\frac{S_{1}}{r_{2}}+\frac{\sigma S_{2}}{\sigma-1}\right]<\infty .
$$

The above inequality is because $r_{2} \rightarrow \infty$ is shown from eq. (14) when $\lambda \rightarrow 0$.

On the other hand,

$$
\begin{aligned}
V_{1} & =\frac{\sigma-1}{c \sigma}\left[\frac{1}{F}\left(\lambda+\phi \frac{1-\lambda}{r_{2}^{\sigma-1}}\right)\right]^{\frac{1}{\sigma-1}}\left[\frac{S_{1}}{(\sigma-1) \lambda}+S_{1}+S_{2} r_{2}\right] \\
> & \frac{\sigma-1}{c \sigma}\left[\frac{1}{F}\left(\phi \frac{1-\lambda}{r_{2}^{\sigma-1}}\right)\right]^{\frac{1}{\sigma-1}} \frac{S_{1}}{(\sigma-1) \lambda}=\frac{S_{1}}{\beta \sigma}\left[\frac{\phi(1-\lambda)}{F}\right]^{\frac{1}{\sigma-1}} \frac{1}{r_{2} \lambda} .
\end{aligned}
$$

In order to compute the term $\frac{1}{r_{2} \lambda}$ for $\lambda \rightarrow 0$, we make use of eq. (14) in the text. Using share $L_{1}+L_{2}=1 \quad L_{1}=\lambda$ and $L_{1}+L_{2}=1$ and multiplying both sides of eq. (14) by $\frac{(\sigma-1)}{r_{2} K_{1} \sigma}$ yields:

$$
\frac{1}{r_{2} \lambda}=\frac{\sigma-1}{\sigma S_{1}}\left[\frac{\frac{S_{1}}{(\sigma-1) r_{2}}+\left(\frac{S_{1}}{r_{2}}+S_{2}\right) \lambda}{\lambda+\phi(1-\lambda) r_{2}^{1-\sigma}}+\phi \frac{\frac{S_{2}}{\sigma-1}+\left(\frac{S_{1}}{r_{2}}+S_{2}\right)(1-\lambda)}{\phi \lambda+(1-\lambda) r_{2}^{1-\sigma}}\right]>\frac{\sigma-1}{\sigma S_{1}}\left[\phi \frac{\frac{S_{2}}{\sigma-1}}{\phi \lambda+(1-\lambda) / r_{2}^{\sigma-1}}\right] .
$$

The term on the right hand side of the equality goes to infinity when $\lambda \rightarrow 0$. This is because $r_{2} \rightarrow \infty$ when $\lambda \rightarrow 0$. It follows that $\lim _{\lambda \rightarrow 0} \frac{1}{r_{2} \lambda}=\infty$ and, hence, $\lim _{\lambda \rightarrow 0} V_{1}=\infty$. We can thus conclude that, and so $\lim _{\lambda \rightarrow 0} \Delta V=\infty$.

In the case of $\lambda \rightarrow 1$, we can similarly show that $\lim _{\lambda \rightarrow 1} \Delta V=-\infty$.

\section{Appendix C}

The symmetry breaking condition is given by

$$
\left.\frac{d \Delta V}{d \lambda}\right|_{\lambda=1 / 2}=0=\left.\frac{d\left(\frac{y_{1}}{G_{1}}-\frac{y_{2}}{G_{2}}\right)}{d \lambda}\right|_{\lambda=1 / 2}=\left.\left(\frac{1}{G_{1}} \frac{d y_{1}}{d \lambda}-\frac{1}{G_{2}} \frac{d y_{2}}{d \lambda}\right)\right|_{\lambda=1 / 2}-\left.\left(\frac{y_{1}}{G_{1}^{2}} \frac{d G_{1}}{d \lambda}-\frac{y_{2}}{G_{2}^{2}} \frac{d G_{2}}{d \lambda}\right)\right|_{\lambda=1 / 2}
$$


where $y_{1} \equiv \frac{Y_{1}}{L_{1}}=\frac{Y_{1}}{\lambda}$ and $y_{2} \equiv \frac{Y_{2}}{L_{2}}=\frac{Y_{2}}{1-\lambda}$ and where all derivatives should all be understood as being evaluated at $\lambda=1 / 2$, henceforth.

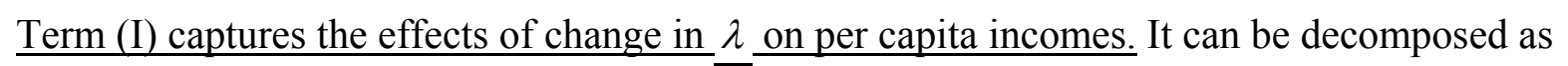
follows. Note first that with $y_{1}=w_{1}+\left(S_{1}+r_{2} S_{2}\right)$ and $y_{2}=w_{2}+\left(S_{1}+r_{2} S_{2}\right)$ and our assumption that the total amount of land is equally owned by the individuals, we have:

$\left(\frac{1}{G_{1}} \frac{d y_{1}}{d \lambda}-\frac{1}{G_{2}} \frac{d y_{2}}{d \lambda}\right)=\left(\frac{1}{G_{1}} \frac{d w_{1}}{d \lambda}-\frac{1}{G_{2}} \frac{d w_{2}}{d \lambda}\right)$. The wage responses can be derived from $w_{1}=\frac{p_{1} q_{1}}{\sigma F}=\frac{1}{\sigma F}\left(\left(\frac{p_{1}}{G_{1}}\right)^{1-\sigma} Y_{1}+\left(\frac{p_{1}}{G_{2}}\right)^{1-\sigma} \phi Y_{2}\right)$ and $w_{2}=\frac{p_{2} q_{2}}{\sigma F}=\frac{1}{\sigma F}\left(\left(\frac{p_{2}}{G_{2}}\right)^{1-\sigma} Y_{2}+\left(\frac{p_{2}}{G_{1}}\right)^{1-\sigma} \phi Y_{1}\right)$.

The overall responses of wages can now be decomposed into

- $\quad$ the effect of market size (i.e. the change in aggregate incomes $Y_{1}$ and $Y_{2}$ induced by a change in $\lambda$ ) on wages; call this the

$$
\text { demand linkage }=\frac{2^{\frac{2 \sigma-3}{\sigma-1}}(1-\phi)\left(\frac{1+\phi}{F}\right)^{\frac{1}{\sigma-1}}\left[(\sigma-1)\left(1+\phi^{2}\right)+2 \phi[3+\sigma(2 \sigma-3)]\right]}{c \sigma(1+\phi)\left[(\sigma-1)(1-\phi)^{2}+4 \sigma^{2} \phi\right]}>0
$$

- the response of wages via the changes in $\left(\frac{p_{1}}{G_{1}}\right)^{1-\sigma}$ and $\left(\frac{p_{1}}{G_{2}}\right)^{1-\sigma}$ for the wage of region 1 and $\left(\frac{p_{2}}{G_{2}}\right)^{1-\sigma}$ and $\left(\frac{p_{2}}{G_{1}}\right)^{1-\sigma}$ for region 2 induced by a change in $\lambda$; call this the product market competition effect

$$
\begin{aligned}
& =\frac{-8 Y_{1}}{\sigma(1+\phi)^{2}}\left[(1-\phi)^{2}-\phi(\sigma-1) \frac{d r_{2}}{d \lambda}\right] \\
& =-\frac{2^{\frac{2 \sigma-3}{\sigma-1}\left(\frac{1+\phi}{F}\right)^{\frac{1}{\sigma-1}}\left[(\sigma-1)+[7+\sigma(8 \sigma-13)] \phi+(3 \sigma-7) \phi^{2}+(\sigma+1) \phi^{3}\right]}}{c \sigma(1+\phi)\left[(\sigma-1)(1-\phi)^{2}+4 \sigma^{2} \phi\right]}<0
\end{aligned}
$$

The product market competition effect is itself composed of two subeffects, the 'traditional' one running through $(1-\phi)^{2}$ and a novel one running through $d r_{2} / d \lambda$.

Note: These two terms add up to (I). 


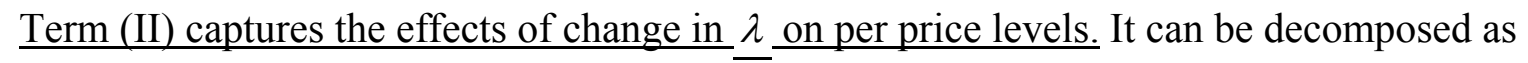
follows. With $G_{1}=\left(\frac{c \sigma}{\sigma-1}\right)\left(\frac{\lambda}{F}+\phi\left(\frac{1-\lambda}{F}\right) r_{2}{ }^{1-\sigma}\right)^{\frac{1}{1-\sigma}}$ and $G_{2}=\left(\frac{c \sigma}{\sigma-1}\right)\left(\frac{\phi \lambda}{F}+\left(\frac{1-\lambda}{F}\right) r_{2}{ }^{1-\sigma}\right)^{\frac{1}{1-\sigma}}$ this effect can be decomposed into

- $\quad$ the effect of a change of $\lambda$ on $G_{1}$ and $G_{2}$ given $r_{2}$; call this the

$$
\text { supply linkage } \quad=\frac{2^{\frac{2 \sigma-3}{\sigma-1}}(1-\phi)\left(\frac{1+\phi}{F}\right)^{\frac{1}{\sigma-1}}}{c(\sigma-1)(1+\phi)}>0
$$

the effect of a change of $\lambda$ on $G_{1}$ and $G_{2}$ transmitted only via $r_{2}$; call this the $\underline{\text { factor market competition effect }}$

$$
=-\frac{2^{\left(\frac{2 \sigma-3}{\sigma-1}\right)}(1-\phi)\left(\frac{1+\phi}{F}\right)^{\frac{1}{\sigma-1}}\left[\sigma[1+(4-\phi) \phi]-\left(1-\phi^{2}\right)\right]}{c(1+\phi)\left[(\sigma-1)(1-\phi)^{2}+4 \sigma^{2} \phi\right]}<0
$$

Note: These two terms add up to (II).

\section{Appendix D}

Proof of Lemma 3. After dividing both sides of eq. (14) by $\sigma$, using $S_{1}=S_{2}=S$ and $r_{2}=1$, and then subtracting the RHS from the LHS we obtain:

$$
\frac{S}{(\sigma-1) \lambda}-\frac{S}{\sigma}\left[\frac{\frac{1}{\sigma-1}+2 \lambda}{\lambda+\phi(1-\lambda)}+\phi \frac{\frac{1}{\sigma-1}+2(1-\lambda)}{\phi \lambda+(1-\lambda)}\right]=-\frac{S(2 \lambda-1)\left[\left(1-\phi^{2}\right)(\sigma-1)(1-\lambda) \lambda+\phi \sigma\right]}{\sigma \lambda^{*}(\sigma-1)[\lambda+\phi(1-\lambda)][\phi \lambda+(1-\lambda)]} .
$$

It is immediately seen that the resulting expression is negative when $\lambda>1 / 2$. Hence, $r_{2}=1$ cannot be a solution (which must equalize LHS and RHS) when the domestic region is larger. Since the expression (LHS - RHS) obtained from eq. (14) is monotone decreasing in $r_{2}$ (recall the proof of lemma 1 which uses the fact that the RHS of eq. (14) is increasing in $r_{2}$ ), and since we know that a solution which equates LHS with RHS does exist, it must be that $r_{2}<1=r_{1}$. 


\section{Appendix E}

Proof of Proposition 5. Using (12) and $S_{1}=S_{2}=S$ the wage differential is calculated to be given by $w_{1}-w_{2}=\frac{\left[1-\lambda\left(1+r_{2}\right)\right] S}{(\sigma-1)(1-\lambda) \lambda}$ which is zero only if $\lambda=1 /\left(1+r_{2}\right)$. Substituting this expression into eq. (14) and $\Delta V=0$, and eliminating $\phi$ yields

$$
g\left(r_{2}\right)\left(r_{2}^{4}-r_{2}^{2 \sigma}\right)\left(r_{2}-r_{2}^{1-2 \alpha}\right)=0
$$

Because we consider asymmetric equilibrium $\lambda>1 / 2$, the relevant interval of $r_{2}$ is confined to $(0,1)$. Since $g\left(r_{2}\right) \neq 0$ in this interval, (26) holds for all $r_{2} \in(0,1)$ if $\sigma=2$ or if $\alpha=1 / 2$. In the case of $\sigma=2,(14)$ leads to $r_{2}=1$, which is outside the interval. Therefore, $\alpha=1 / 2$ is the only case that satisfies $w_{1}=w_{2}$ as well as the equilibrium conditions of (14) and $\Delta V=0$ for asymmetric equilibrium $\lambda>1 / 2$. Put differently, if $\alpha \neq 1 / 2$, then $w_{1} \neq w_{2}$. This implies that insofar as $\alpha<1 / 2$, the sign of $w_{1}-w_{2}$ remains unchanged, and so does $\alpha>1 / 2$.

Suppose $\alpha<1 / 2$. If $\lambda$ approaches 1 , eq. (15) leads to

$$
\lim _{\lambda \rightarrow 1} \frac{w_{1}}{w_{2}}=\lim _{\lambda \rightarrow 1} \frac{S_{1}}{S_{2}} \frac{1-\lambda}{\lambda} \frac{1}{r_{2}}=0
$$

because $\lim _{\lambda \rightarrow 1} r_{2} \lambda=+\infty$ holds from the end of appendix A. This means that $w_{1}<w_{2}$ holds for all $\alpha<1 / 2$ whenever $\lambda>1 / 2$ is a stable equilibrium.

When $\alpha>1 / 2$, the opposite argument applies leading to $w_{1}>w_{2}$. 


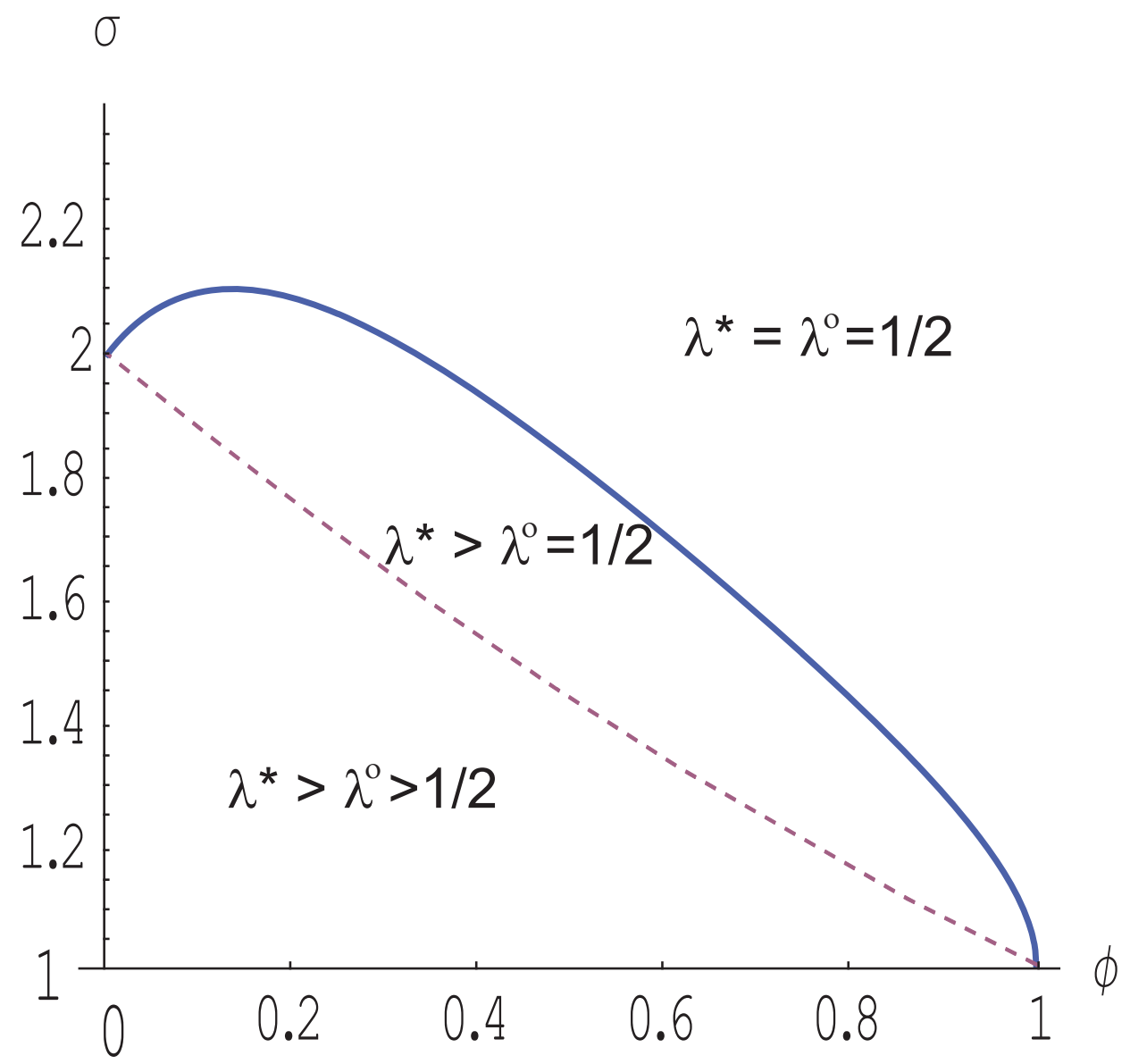

Figure 1: Equilibrium and optimum for given values of $\phi$ and $\sigma$ when land is used for production 


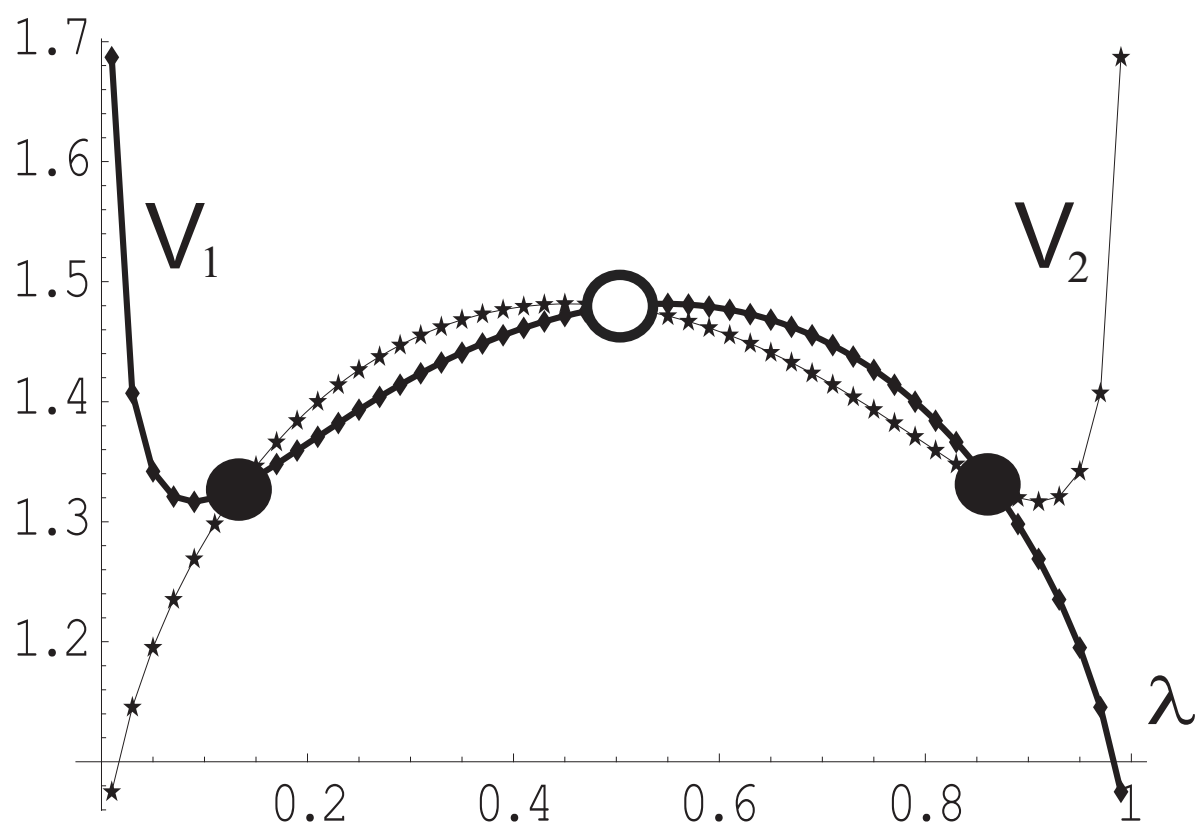

Our model with $\phi=0.72$, and $\sigma=1.5$

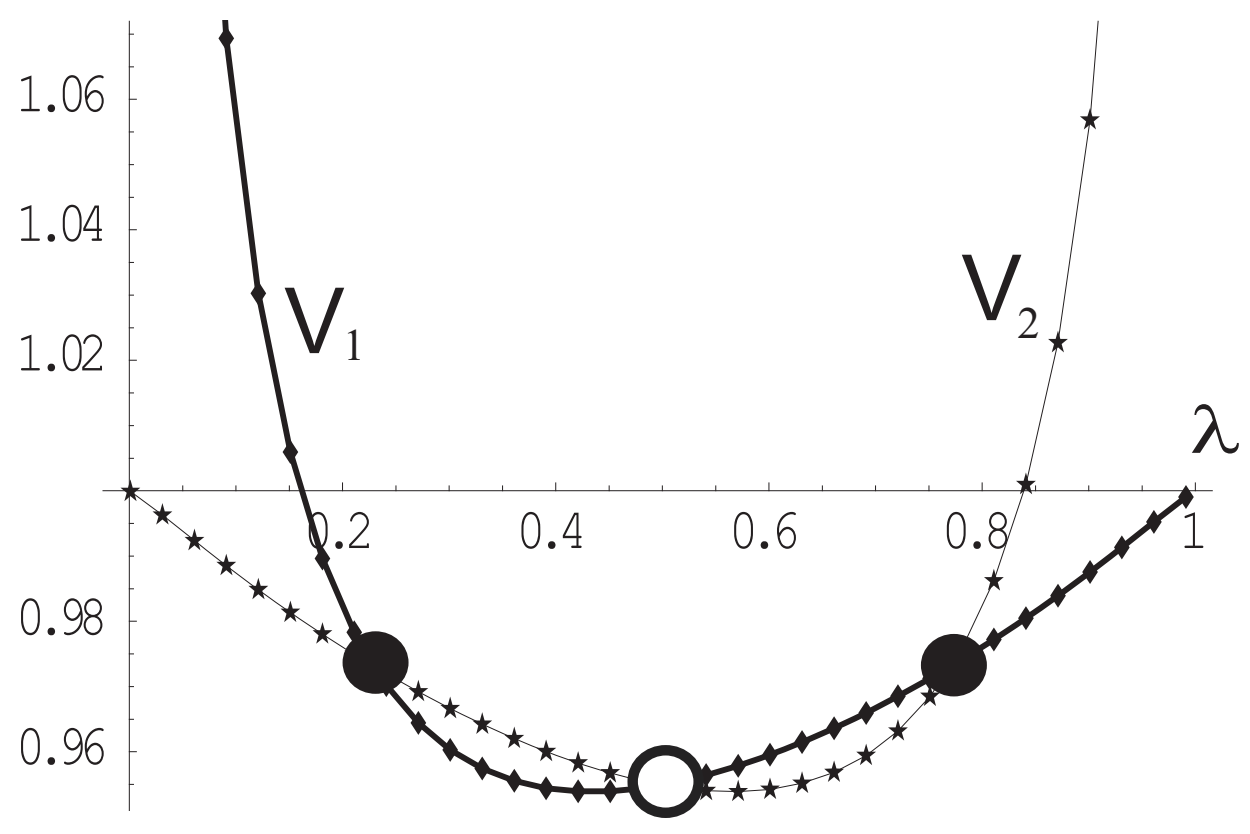

Helpman's model with $\alpha=0.4, \phi=1 / 6$, and $\sigma=2$

Figure 2: Our model and Helpman's model near symmetry break 

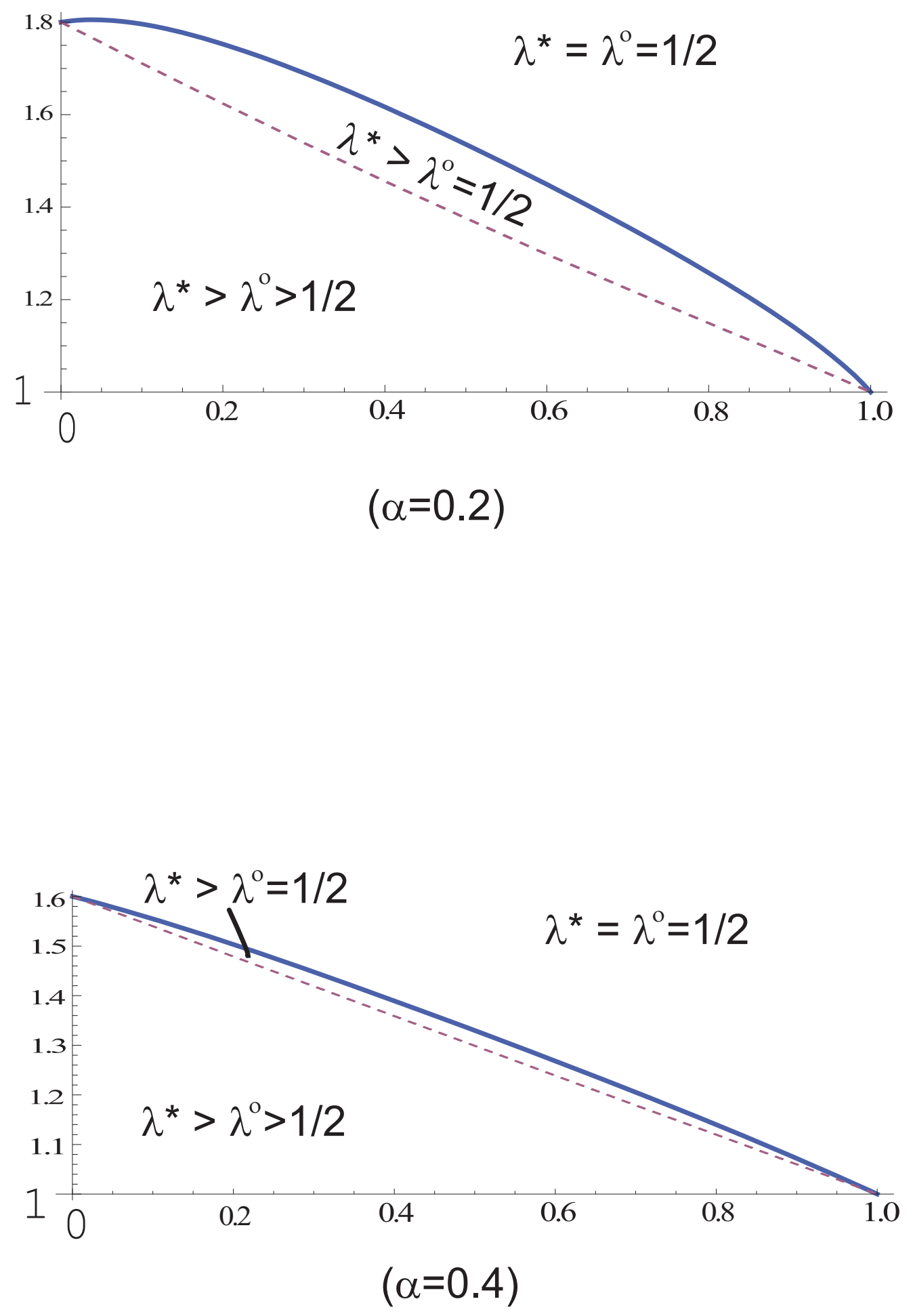

Figure 3: Equilibrium and optimum for given values of $\phi$ and $\sigma$ when land is used for production and housing 